\title{
The Clinical and Pathological Features of Colorectal Cancer in Tabuk Region, Saudi Arabia: Trends in the Young and Elderly Patients
} Ahmad A. A. Abdullah Omer

Department of Surgery, Faculty of Medicine, University of Tabuk, Saudi Arabia

\section{Abstract}

Background: Colorectal cancer (CRC) is common in the Kingdom of Saudi Arabia (KSA) and worldwide. Tabuk region, in the Northwest part of Saudi Arabia, is one of the regions with the highest incidence of the disease in the Kingdom.

Objective: This study aims to compare the clinicopathological features of CRC between the young and elderly patients in Tabuk region.

Methods: This is a retrospective, hospital-based, descriptive study conducted at the three main referral hospitals in Tabuk region over 5-year period between 2010 and 2014. All patients diagnosed with CRC proved with histopathology were retrieved and categorized into two groups; group one (less than 40 years of age) and group two (equal to or older than 40 years of age). The clinical and pathological features of the disease were compared between the two groups.

Results:The study involved 72 patients $94.4 \%$ of whom were Saudi and 5.6\% were from the South East population. Group one comprised 10 patients $(13.9 \%)$ while group two were $62(86.1 \%)$. The male to female ratio was 1.5 for group one and 1.7 for group two. Adenocarcinoma was the predominant histological type in both groups (98.6\%). Lefts-sided tumours were more common in both groups (74.2 and 70\%) however; a greater proportion of the patients in group 1 had more right-sided tumours (30\%) than their elderly counterparts (25.8\%). Advanced tumour presentation (Duke`s C+D) was more common in group $1(90 \%)$ than in group $2(83.8 \%)$. However, differences between the two groups was not statistically significant.

Conclusion: CRC is less common among the young population in Tabuk region than other parts of Saudi Arabia and some regional countries. Demographic and genetic studies are advocated in the area to provide further explanation of these results.

\section{Introduction}

Colorectal cancer (CRC) is one of the leading causes of cancer and cancer-related deaths worldwide [1]. The WHO has estimated that 774,000 people have died of CRC all over the world in 2015 (WHO website). In the Kingdom of Saudi Arabia (KSA), colorectal cancer accounted for $11.9 \%$ of all newly diagnosed cancer in 2013. The disease is ranked the first among males and the third among females with an age-adjusted incidence of $11.0 \%$ in both sexes[2]. The dramatic rise in the incidence of the disease that the area have seen is related to possible genetic and environmental factors [3-5]. The rapid urbanization and modernization that have accompanied the oil boom have induced an immense change in the lifestyle of the population, particularly their diet and the habit of smoking [6].

Although CRC is commonly diagnosed inelderly people, it is being increasingly encountered in young subjects. This shift in the pattern of the disease has been demonstrated in the KSA as well as in other developing countries [7]. Aljebreen [8], in a study of 113 CRC patients at King Khalid University Hospital in Riyadh has found that $37 \%$ of the patients were younger than 50 years. He concluded that Saudi patients tend to present with CRC at a younger age and with advanced presentation. Strikingly, Guraya and Eltinay [9] in a study of 47 CRC patients in Riyadh, the central region of KSA, have found that $63 \%$ of the patients are younger than 40 years. They have concluded a higher prevalence of the disease among young Saudi population. Eltinay and Guraya [10] have made a similar conclusion with an average age of 42.7 years among the patients in their series most of whom (76.9\%) have an advanced stage at presentation. Another study in Al-Hassa Region in the Eastern Province of Saudi Arabia has declared that $15.5 \%$ of CRC patients were younger than 40 years.
Publication History:

Received: June 06, 2017

Accepted: October 04, 2017

Published: October 06, 2017

\section{Keywords:}

Colorectal cancer, Young, Elderly, Tabuk, Saudi Arabia
It added that males tend to be affected at a younger age more than females [11], but this is contradicted by Isbister et al. [7] at King Faisal Specialist Hospital in Riyadh who also found that $20 \%$ of the patients with rectal cancer in his series are less than 40 years of age. Ayyub et al. [12] in a study at King Abdul-Aziz hospital in Jeddah, Western region of the KSA, have shown that $17.5 \%$ of the patients were below the age of 40 years. In a subsequent study at the same hospital, Mansoor et al. [13] have found that $21 \%$ of the patients in their series presented in their third decade of life and that a greater percentage of them have presented with rectal bleeding than their elderly counterparts. Studies in some neighbouring countries in the Gulf region, Middle East and Africa have consistently shown an increased tendency of CRC to affect young individuals more than in the high-risk areas like USA and Europe [14-21].

Tabuk region, in the North West part of KSA, comes on the top of the list of the regions with the highest incidence in the kingdom (cancer incidence report, 2013). Despite this fact, only few studies have been carried out to explore the features and the characteristics of the disease in the area. This study aims to explore the clinical and pathological features of the disease in the young and elderly

"Corresponding Author: Dr. Ahmad Abdul Azeem Abdullah Omer, Department of Surgery, Faculty of Medicine, University of Tabuk, P.O. Box: 3718, Tabuk 71481, Saudi Arabia, Tel: +966538125386; E-mail: a.omer@ut.edu.sa

Citation: Abdullah Omer AAA (2017) The Clinical and Pathological Features of Colorectal Cancer in Tabuk Region, Saudi Arabia: Trends in the Young and Elderly Patients. Int J Surg Surgical Porced 2: 122. doi: https://doi.org/10.15344/2456$4443 / 2017 / 122$

Copyright: (C) 2017 Abdullah Omer. This is an open-access article distributed under the terms of the Creative Commons Attribution License, which permits unrestricted use, distribution, and reproduction in any medium, provided the original author and source are credited. 
Citation: Abdullah Omer AAA (2017) The Clinical and Pathological Features of Colorectal Cancer in Tabuk Region, Saudi Arabia: Trends in the Young and Elderly Patients. Int J Surg Surgical Porced 2: 122. doi: https://doi.org/10.15344/2456-4443/2017/122

Page 2 of 4

population in Tabuk region building on the similar results in other parts of the KSA. While this would provide some insight into the disease characteristics in the region, it would also help set the stage for future research to explore the topic at a deeper level.

\section{Methods}

The study design is a retrospective hospital-based descriptive one conducted in the three main referral hospitals in Tabuk region namely; King Khalid Hospital, King Fahd Hospital, and KingSalman North-west armed forces Hospital. Data of all patients presented with CRC tumors over 5-year period between 2010 and 2014 were retrieved from the patients' records at the departments of statistics in the three hospitals. Patients are grouped into two categories; group one who are patients younger than the age of forty, and elderly patients who are 40 years of age or older. Demographic characteristics of the patients, the clinical mode of presentation, the pathological features and the stage of the tumors, in addition to the treatment modalities applied are compared between the two groups. Data were analyzed using the "Statistical Package of Social Sciences" computer software (SPSS Inc. Illinois, Chicago) version 16. Descriptive statistics are presented in the form of frequency and percentage while the statistical significance of the relations among the data is examined using the Chi-square test. The Ethical Committee at King Salman Armed Forces Hospital in the Northwest region granted an ethical approval for the conduct of this study.

\section{Results}

The study included 73 patients who were diagnosed with CRC in the three hospitals during the study period. One patient was excluded due to poor record. Sixty-seven patients were Saudi (94.4\%) while four patients were non-Saudi (5.6\%) who were from the South East Asian population.Group (1) patients $(<40$ years $)$ were 10 while group (2) patients ( $\geq 40$ years) were 62 . Thus $13.9 \%$ of the patients with CRC in the region are young patients below the age of 40 years. In group (1), males were six $(60 \%)$ while females were four (40\%). Among group (2) patients, males were 39 (62.9\%) while females were 23 (37.1\%).Intestinal obstruction was the most common form of emergency presentation noted in all patients in both groups (95.5\%) except one patient (4.5\%) who presented with intestinal perforation and peritonitis in the elderly patients. Regarding the non-emergency presentation, rectal bleeding was the most common form in group 2 recognized in 20 patients (29\%) while 6 patients in group 1 have presented with alteration of bowel habits, rectal bleeding and abdominal mass (two patients in each (20\%)). Adenocarcinoma was the prevalent histological type in both groups (98.6\%) except one case of lymphoma (1.4\%) which was discovered in the elderly group. Summary of the clinical presentation, tumor subsite, histological grade, Duke's stage and the treatment applied in each group is presented in table 1 .

\section{Discussion}

The incidence of CRC in Tabuk region has risen to the double in the last two decades since the publication of the first cancer registry report in the KSA in 1996 [2]. A recent study in the area has shown that the disease is common and that patients tend to present at an advanced stage [22]. These findings necessitate a greater concentration on the topic to delineate its characteristic features in this part of the Kingdom and to help devise suitable strategies to overcome its consequences.

\begin{tabular}{|c|c|c|c|c|}
\hline No & Item & Group 1 & Group 2 & Chi-square \\
\hline \multirow[t]{4}{*}{1.} & \multicolumn{4}{|l|}{ CLINICAL PRESENTATION: } \\
\hline & Acute & $4(40 \%)$ & $18(29 \%)$ & \multirow{3}{*}{0.485} \\
\hline & Cold & $6(60 \%)$ & $44(71 \%)$ & \\
\hline & Total & $10(100 \%)$ & $62(100 \%)$ & \\
\hline \multirow[t]{13}{*}{2.} & \multicolumn{4}{|l|}{ TUMOR SITE: } \\
\hline & \multicolumn{4}{|l|}{ Right-sided: } \\
\hline & Cecum & $1(10 \%)$ & $6(9.7 \%)$ & \multirow{5}{*}{0.719} \\
\hline & Ascending colon & 0 & $2(3.2 \%)$ & \\
\hline & Hepatic flexure & $2(20 \%)$ & $5(8.1 \%)$ & \\
\hline & Transverse colon & 0 & $3(4.8 \%)$ & \\
\hline & Total & $3(30 \%)$ & $16(25.8 \%)$ & \\
\hline & \multicolumn{4}{|l|}{ Left-sided: } \\
\hline & Splenic flexure & $1(10 \%)$ & $4(6.5 \%)$ & \multirow{5}{*}{0.933} \\
\hline & Descending colon & 0 & $2(3.2 \%)$ & \\
\hline & Sigmoid & $2(20 \%)$ & $18(29 \%)$ & \\
\hline & Rectum & $4(40 \%)$ & $22(35.5 \%)$ & \\
\hline & Total & $7(70 \%)$ & $46(74.2 \%)$ & \\
\hline \multirow[t]{5}{*}{3.} & \multicolumn{4}{|l|}{ TUMOR DIFFERENTIATION: } \\
\hline & Well-differentiated & $3(30 \%)$ & $15(24.2 \%)$ & \multirow{4}{*}{0.474} \\
\hline & Moderately differentiated & $7(70 \%)$ & $38(61.3 \%)$ & \\
\hline & Poorly-differentiated & 0 & $8(12.9 \%)$ & \\
\hline & Total & $10(100 \%)$ & $61(98.4 \%)^{*}$ & \\
\hline \multirow[t]{6}{*}{4.} & DUKE'S STAGE: & & & \\
\hline & B & 0 & $6(9.7 \%)$ & \multirow{5}{*}{0.741} \\
\hline & $\mathrm{C} 1$ & $3(30 \%)$ & $14(22.6 \%)$ & \\
\hline & $\mathrm{C} 2$ & $3(30 \%)$ & $21(33.9 \%)$ & \\
\hline & $\mathrm{D}$ & $3(30 \%)$ & $17(27.4 \%)$ & \\
\hline & Total & $9(90 \%)^{*}$ & $58(93.5 \%)^{*}$ & \\
\hline \multirow[t]{11}{*}{5.} & TREATMENT APPLIED: & & & \\
\hline & Curative: & & & \\
\hline & Abdominoperineal resection & 0 & $5(8.1 \%)$ & \multirow{5}{*}{0.815} \\
\hline & Anterior resection & $1(10 \%)$ & $4(6.5 \%)$ & \\
\hline & Right hemicolectomy & $2(20 \%)$ & $13(21 \%)$ & \\
\hline & Left hemicolectomy & $3(30 \%)$ & $18(29 \%)$ & \\
\hline & Total & $6(60 \%)$ & $40(64.5 \%)$ & \\
\hline & \multicolumn{4}{|l|}{ Palliative: } \\
\hline & Colostomy & $3(30)$ & $8(12.9 \%)$ & \multirow[t]{3}{*}{0.156} \\
\hline & Chemoradiation & $1(10)$ & $10(16.1 \%)$ & \\
\hline & Total & $4(40 \%)$ & $18(29 \%)^{\star}$ & \\
\hline
\end{tabular}

Table 1): Clinical presentation, tumor site, tumor grade, Duke's stage, and the treatment applied in young and elderly patients $(\mathrm{N}=72$, Group $(1)$ $=10$ and group $(2)=62$ )

*missing values.

In this study, around $14 \%$ of the patients were younger than 40 years of age. This percentage is less than the recorded figures in the Eastern, Central and Western regions of the KSA [6-9,11]. The increased incidence of CRC in the young individuals has been related to the increasing size of the young population as has been shown by some studies in the gulf region and some neighboring countries. Population studies in the Middle East have shown a dramatic increase in the number of populations which was attributed to high rates of fertility and decreased mortality. 
Citation: Abdullah Omer AAA (2017) The Clinical and Pathological Features of Colorectal Cancer in Tabuk Region, Saudi Arabia: Trends in the Young and Elderly Patients. Int J Surg Surgical Porced 2: 122. doi: https://doi.org/10.15344/2456-4443/2017/122

Page 3 of 4

Moreover, the major proportion of the population lies in the young age [23]. One study in Qatar has asserted a different age pyramid in the country than Western communities in which the balance is remarkably shifted towards the young population [16]. This pattern has also been approved in the United Arab Emirates, Egypt and Jordan $[14,15,19]$. In the KSA, Almalki et al. [24] have indicated that $67.1 \%$ of the population are under the age of 30 years and only $5.2 \%$ of the population are above the age of 60 . These figures when read in conjugation with the high prevalence of obesity and overweight and the alarming figures of smoking among young subjects in the Kingdom, may clearly explain the higher prevalence of CRC among the young population $[25,26]$. Genetics has been proposed as a factor that may explain the increased tendency of CRC to inflict young subjects as has been approved by some studies in the KSA and some countries in the region $[15,19]$. AlJebreen $[8]$ has pointed to a "hidden" familial risk of CRC for the young individuals in KSA, which require further and in-depth analysis. Amin et al. [11] have reported similar result in the Eastern part of KSA. Bader and Ismail [3] have identified KRAS mutation in $42.2 \%$ of CRC patients in their series of whom the majority were between 40 and 60 years of age. They have concluded that the frequency of these mutations appears high in the Saudi population but they called for further studies at the level of the whole country to yield generalizable results [2]. Al-Kuraya et al. [27] have depicted some gene alterations in the Saudi population, which they accused for the increased number of CRC in the KSA. In contrary, Ayyub et al. [12] and Mansoor et al. [13] did not observe familial predisposition for CRC in their series. The former have concluded that the disease may arise in the young patients in particular without any predisposing factor. The lower frequency of CRC in young patients in Tabuk region in comparison to other parts of the KSA could be related to different genetics, which play in the area. Isbister et al. [7] have noted that family history does not play an important role in CRC pathogenesis in KSA. They pointed to the fewer CRC genes in the Saudi population, which they related to the "protected gene pool" in KSA that could be explained by the closed consanguinity marriage in the kingdom [7]. Environmental factors were postulated also to play a role in the increased incidence of CRC in the young patients $[17,19]$. While these factors are expected to affect the whole population, young individuals could have an increased exposure and susceptibility to develop the disease [14]. To sum up at this stage, there is a need for demographic and genetic studies in Tabuk region to elaborate more on the pathogenesis of CRC in the area and further explain the finding of this study.

Similar proportions of males and females are affected in the young and elderly groups in this study, which is consistent with the finding of Isbister et al. [7] in Riyadh, central part of the KSA. In contrary, Amin et al. [11] in the Eastern province of the KSA have concluded that males are affected at a younger age than females. Mansoor et al. [13] have observed relatively fewer males (43\%) and more females (57\%) in CRC patient younger than 50 years in comparison to their elderly counterparts ( $58 \%$ and $42 \%$ respectively). These contradicting results could be explained by geographical differences in the distribution of males and females among the population and requires further exploration.

No significant differences were noted between the two groups in terms of the clinical presentation, tumor subsite, tumor differentiation, Duke's stage and the treatment applied in accordance with Aljebreen [8] who concluded the same. However, it is of note that although left-sided tumors are more common than right-sided tumors in bothgroups, a greater proportion of the young patients had more right- sided tumors and fewer left-sided tumors in comparison to their elderly counterparts. This agrees with the finding of Isbister [28] in Riyadh, the capital city of the KSA, who have observed more proximal lesions in CRC patientswho are younger than 40 years [28]. Guraya and Eltinay [9] have claimed a rightward shift in the pattern of CRC in Saudi Arabia where almost two third of the patients in their series were younger than 40 years. However, Eltinay and Guraya [9] and Amin et al. [11] in the KSA and Al-Jabri et al. [15] in Jordan have reported different findings, which manifest more left-sided tumors in the young patients and a proximal shift of CRC tumors in elderly patients. These results could be attributed to variations in the behavior of the tumor in the young and elderly patients or may clue an increased number of colonoscopies being done owing to the wide availability of the technique nowadays in the KSA, which resulted in identification of more proximal tumors in the young patients[6, 9]. Another finding in this study, although not significant, is that advanced presentation (Duke's $\mathrm{C}+\mathrm{D}$ ) was recognized slightly more in the young patients $(90 \%)$ in comparison to their elderly counterparts $(83.8 \%)$. This is congruent with the findings of many studies, which have linked young patients to an advanced presentation and less favorable prognosis $[7,8,10,13,15,17]$.This could also be related to a difference in the biological behavior of the tumor between the young and elderly patients [9] and necessitates the establishment and execution of an effective screening program to improve the poorer outcome of the disease in the young population. The author hopes that this study would set the stage for further research to elaborate more on these findings and explore them at a greater depth.

\section{Conclusion}

It was observed in this study that CRC is less common among the young population in Tabuk region than in other geographical parts of the KSA and surrounding countries. There is a slight propensity of the tumor to be encountered in the right side of colon and to present at an advanced stage among the young patients in comparison to their elderly counterparts. The general clinical and pathological features of the disease among the young and elderly patients in the region are consistent with what is reported in other parts of the Kingdom and regional countries. Demographic, genetic and environmental studies would help shed more light on the topic and further explain the findings of this study in the area and are consequently strongly recommended.

\section{Competing Interests}

The authors declare that they have no competing interests.

\section{Acknowledgements}

I would like to thank Mr. Osama Mukhtar in the Oncology department at King Salman Armed Forces Hospital in the Northwest region, and the officers in the department of statistics in King Khalid Hospital and King Fahd Hospital, who provided generous help during the process of data collection. I would like also to express my gratitude to Dr. Ehab Ahmed Farah who supervised the process of data analysis and to the Deanship of research in the University of Tabuk, which supported and funded this work

\section{Funding}

This study is funded by the Deanship of Research in the University of Tabuk. 
Citation: Abdullah Omer AAA (2017) The Clinical and Pathological Features of Colorectal Cancer in Tabuk Region, Saudi Arabia: Trends in the Young and Elderly Patients. Int J Surg Surgical Porced 2: 122. doi: https://doi.org/10.15344/2456-4443/2017/122

\section{References}

1. Siegel RL, Miller KD, Jemal A (2015) Cancer statistics, 2015. CA Cancer J Clin 65: 5-29.

2. Saudi Cancer Registry, Cancer Incidence Reports, Saudi Arabia (2013, 2011 \& 1996)

3. Bader T, Ismail A (2014) Higher prevalence of KRAS mutations in colorectal cancer in Saudi Arabia: Propensity for lung metastasis. Alexandria journal of medicine 50: 203-209.

4. Zubaidi A (2008) Multiple primary cancers of the colon, rectum, and the thyroid gland. The Saudi J Gastroenterol 14: 202-205.

5. Al-Ahwal M, Shafik Y, Al-Ahwal H (2013) First national survival data fo colorectal cancer among Saudis between 1994 and 2004: what's next? BMC Public Health 13: 73.

6. Al-Radi A, Ayyub M, Al-Mashat F, Barlas S, Al-Hamdan, et al. (2000) Primary gastrointestinal cancers in the Western region of Saudi Arabia, Is the pattern changing. Saudi Med J 21: 730-734.

7. Isbister W, Murad M, Habib Z (2000) Rectal cancers in the kingdom of Saudi Arabia: the King Faisal Specialist Hospital experience. Aus NZJ Surg 70: $269-274$

8. Aljebreen A (2007) Clinico-Pathological patterns of colorectal cance in Saudi Arabia: younger with an advanced stage presentation. Saudi J Gastroenterol 13: 84-87.

9. Guraya SY, Eltinay OE (2006) Higher prevalence in young population and rightward shift of colorectal carcinoma. Saudi Med J: 27: 1391-1393.

10. Eltinay O, Guraya S (2006) Colorectal carcinoma: clinic-pathological pattern and outcome of surgical management. Saudi J Gastroenterol 12: 83-86.

11. Amin T, Suleman W, Taissan A, Al Joher A, Al mulhim O, et al. (2012) Patients' profile, clinical presentations and histopathological features of colo-rectal cancer in Al Hassa region, Saudi Arabia. Asian Pacific J Cancer Prev 13: 211-216.

12. Ayyub M, Al-Radi A, Khazeindar A, Nagi A, Maniyar I (2001) Clinicopathological trends in colorectal cancer in a tertiary care hospital. Saudi Med J 23: 160-163.

13. Mansoor I, Zahrani I, Abdul Aziz S (2002) Colorectal cancers in Saud Arabia. Saudi Med J 23: 322-327.

14. Gado A, Ebeid B, Abdelmohsen A, Axon A (2014) Colorectal cancer in Egypt is commoner in young people; is this cause for alarm? Alexandria Journal of Medicine: 50: 197-201.

15. Al-Jabri T, Yaghan R, El-Heis H (2003) Colorectal cancer in young patients under 40 years of age, Comparison with old patients in a well defined Jordanian population. Saudi Med J 24: 871-874.

16. Rasul K, Awidi A, Mubarak A, Al-Homsi U (2001) Study of colorectal cancer in Qatar. Saudi Med J 22: 705-707.

17. Bakari A, Nggada H, Adamu A, Gali M, Deba U, et al. (2014) Presentation and management of colorectal cancer in under 40 years of age in the SubSaharan Africa: A multi-centre study. Sch J App Med Sci 2: 3284-3288.

18. Abdalla A, Musa T, Khair R (2007) Presentation of colorectal cancer in Khartoum Teaching Hospital. Sudan JMS 2: 263-256.

19. Al-Shamsi S, Bener A, Al-Sharhan M, Al-Mansoor T, Azab I, et al. (2003) Clinicopathological pattern of colorectal cancer in the United Arab Emirates. Saudi Med J 24: 518-521.

20. Missaoui N, Jaidaine L, Abdelkader A, Beizig N, Anjorin A, et al. (2010) Clinicopathological patterns of colorectal cancer in Tunisia. Asian Pacific Cancer Prev: 11: 1719-1722.

21. Basaleem H, Al-Sakkaf K (2004) Colorectal cancer among Yemeni patients characteristics and patterns. Saudi Med J 25: 1002-1005.

22. Abdullah A, Elnibras M, El-Zahrani O, Mahmoud M, Albalawi I (2016) Clinicopathological Pattern of Colorectal Cancer in Tabuk Region, Saudi Arabia. Glo Adv Res J Med Med Sci 5: 264-268.

23. Omran AR, Roudi F (1993) The Middle East population puzzle. Population Bulletin 48: 1-40
24. Almalki M, Fitzgerald G, Clark M (2011) Health care system in Saudi Arabia: an overview. EMHJ 17: 784-793.

25. Al-Othaimeen A, Al-Nozha M, Osman AK (2007) Obesity: An emerging problem in Saudi Arabia. Analysis of data from the national nutrition survey. Eastern Mediterranean Health Journal 13: 441-448.

26. Al Ghobain MO, Al Moamary MS, Al Shehri SN, AL-Hajjaj MS (2011) Prevalence and characteristics of cigarette smoking among 16 to 18 years old boys and girls in Saudi Arabia. Ann Thorac Med 6: 137-140.

27. Al-Kuraya K, Bavi P, Ezzat A, Al-Dayel F, Uddin S, Atizado V (2006) Colorectal carcinoma from Saudi Arabia: Analysis of $\mathrm{MLH}-1, \mathrm{MSH}-2$ and p53 genes by immunohistochemistry and tissue microarray analysis. Saudi Med J 27: 323-328.

28. Isbister W (1992) Colorectal cancer below age 40 in the Kingdom of Saud Arabia. ANZ Journal of Surgery 62: 468-472. 